\title{
Non-opsonic phagocytosis of Trichophyton mentagrophytes arthroconidia by human neutrophils in vitro
}

\author{
M. D. RICHARDSON and YVONNE BELL \\ Regional Mycology Reference Laboratory, Department of Dermatology, University of Glasgow, 56 Dumbarton Road, \\ Glasgow G11 6NU
}

\begin{abstract}
Summary. A non-opsonic mechanism of binding and phagocytosis by human neutrophils of Trichophyton mentagrophytes arthroconidia is described. This was in direct contrast to the complement dependency of Candida albicans phagocytosis. Both serum complement and specific antibody to T. mentagrophytes promoted maximal phagocytosis $(61 \%$ and $40 \%$ of neutrophils, respectively, contained arthroconidia). Increasing the ratio of arthroconidia to neutrophils did not increase non-opsonic phagocytosis (18-26\%). Phagocytosis of arthroconidia exposed to trypsin in the absence of opsonin was not affected $(18 \%)$. However, proteinase and chitinase reduced the level of non-opsonic and opsonic phagocytosis to negligible levels (6.3\% and $4.5 \%$, respectively). When mannose was added to neutrophils, mannose receptors on the phagocyte membrane were partially blocked when arthroconidia were opsonised, but this did not reduce the level of non-opsonic phagocytosis. The nonopsonic mechanism proposed here may have direct relevance in skin sites poor in opsonins.
\end{abstract}

\section{Introduction}

The mechanisms that defend the host against dermatophyte infections can be divided arbitrarily into local defences, such as the skin, and systemic defences, such as the non-specific and specific immune systems. ${ }^{1}$ The skin is a tough, resistant, multi-layered structure whose main function is protection. The epidermis is proliferating constantly and corneocytes are shed from its surface. For dermatophytes to establish an infection, the fungus must adhere and germinate rapidly. ${ }^{2,3}$ The growth of the fungus must keep pace with the rate of epidermopoiesis and exfoliation.

Antibody responses occur both in inflammatory and non-inflammatory types of infection. Antibody appears to have no protective effect in dermatophytosis. Systemic immunological responses induced by dermatophytes are both antibody- and cellmediated. The non-inflammatory system is the primary defence of the non-immune host because it does not require previous exposure to the invading organism for activation and can respond immediately to protect the host against an invading fungus.

A very early event in the host reaction to invasion by

Received 23 Aug. 1994; accepted 11 Oct. 1994. dermatophytes is the infiltration of neutrophils and epidermal oedema, ${ }^{4}$ and to a lesser extent accumulation of monocytes in the epidermal infiltrateprobably in response to chemotactic components, e.g., C5a, via the alternative complement pathway. ${ }^{5,6}$ The accumulation of phagocytes in the epidermal infiltrates is believed to play an important role in the initial host defence to the invasion of dermatophyte germlings. The precise role played by chemotactic epidermal cytokines such as interleukin 8 in the accumulation of neutrophils at the site of dermatophyte infection is not clear. ${ }^{7}$ Dermatophytes are damaged by toxic oxidative products produced by neutrophils and are destroyed by neutrophils extracellularly. ${ }^{6,8,8-10}$ Previous studies have used saprophytic microconidia only. ${ }^{9,10}$ Arthroconidia are the only infective conidia produced under parasitic conditions and are the natural pathogenic elements of dermatophytes since they are the only form of conidia found in tissues. ${ }^{11}$ Current understanding of the interaction between human effector cells and dermatophytes is very limited.

In the present study the interaction between human neutrophils and arthroconidia of Trichophyton mentagrophytes was characterised in a monolayer assay. The non-opsonic mechanism proposed may have direct relevance in skin sites which are poor in opsonins. 


\section{Materials and methods}

\section{Organisms and stock culture}

One strain of $T$. mentagrophytes (strain 126) which had been preserved on silica gel at $4^{\circ} \mathrm{C}$ was used. Initially, it was recovered from silica gel by growth on glucose peptone agar (GPA) at $28^{\circ} \mathrm{C}$. Subcultures were maintained on GPA and incubated at $28^{\circ} \mathrm{C}$ for 10 days to obtain an optimal yield of fungal growth.

\section{Production and preparation of arthroconidia}

Arthroconidia were prepared as pure suspensions of separated cells from 10-day-old cultures grown as surface lawns on glucose $4 \%$, peptone $1 \%$ agar in an atmosphere of $\mathrm{CO}_{2} 10 \%$, air $90 \%$ at $28^{\circ} \mathrm{C}$ in an incubation module (Flow Laboratories, Irvine), and flushed through daily with $\mathrm{CO}_{2} 10 \%$, air $90 \%$. Surface growth was harvested from the culture plate with a scalpel blade, suspended in phosphate-buffered saline (PBS), $\mathrm{pH} 7 \cdot 2$, and agitated for $5 \mathrm{~min}$. The suspension was filtered through column chromatography grade glass wool to remove chains of arthroconidia, washed three times by agitation in PBS followed by centrifugation at $300 \mathrm{~g}$ for $3 \mathrm{~min}$. The spore suspension was adjusted to a final concentration of $1 \times 10^{7} / \mathrm{ml}$ in PBS. This procedure resulted in a pure, uniform arthroconidial suspension of single cells. No obvious damage to arthroconidia occurred. Viability of singlet arthroconidia was determined by incubation in Sabouraud's dextrose broth for $16 \mathrm{~h}$ at $37^{\circ} \mathrm{C}$. An arthroconidium was considered to have germinated when a visible germ tube had developed. The percentage germination for the strains was 97.00 SD $1.89 \%$.

\section{Preparation of neutrophil monolayers}

Monolayers of glass-adherent neutrophils were prepared as described previously. ${ }^{12}$ Briefly, drops of blood from finger tip punctures (a single donor was used throughout) were placed on $16-\mathrm{mm}$ diameter coverglasses. The blood drops were incubated for $30 \mathrm{~min}$ at $37^{\circ} \mathrm{C}$ in a humidified chamber. They were then immersed in saline $0.85 \% \mathrm{w} / \mathrm{v}$ at $37^{\circ} \mathrm{C}$ and agitated to remove adherent red cells. The coverglasses were then washed again in saline, resulting in confluent neutrophil monolayers.

\section{Assessment of phagocytosis}

Neutrophil monolayers were placed in the wells of "Repli" (Sterilin) tissue culture plates containing $1 \mathrm{ml}$ of $1 \times 10^{5}$ conidial suspension. Normal human serum $(100 \mu \mathrm{l})$ was added to each monolayer immediately before incubation at $37^{\circ} \mathrm{C}$ for $30 \mathrm{~min}$. The monolayers were then washed twice in saline $0.85 \%$ and inverted over glass cavity slides. Monolayers were examined within $5 \mathrm{~min}$ under high power ( $\times 100$ objective) oil immersion microscopy. Ten randomly selected fields of view were examined; the only constraint being that at least two neutrophils were present in each field. The total number of neutrophils per field was counted and the number of neutrophils ingesting one or more conidia was recorded. From these observations, the percentage phagocytosis (number of neutrophils with one or more ingested conidia/total neutrophil number) was calculated.

\section{Exposure of arthroconidia to trypsin, proteinase and chitinase}

To determine the contribution of outer cell wall components to neutrophil binding and phagocytosis, arthroconidia were exposed to various site-specific cell wall solubilising enzymes and the treated spores were added to standard neutrophil monolayer assays. Trypsin (Sigma) was prepared as a $0.25 \%$ solution in PBS and used to reconstitute a pellet of arthroconidia $\left(3 \times 10^{6}\right.$ arthroconidia $\left./ \mathrm{ml}\right)$. The spore suspension was incubated for $60 \mathrm{~min}$ at $37^{\circ} \mathrm{C}$ and then washed three times. Proteinase ( $1 \mathrm{mg}$; Sigma) was added to the same concentration of arthroconidia and incubated for $18 \mathrm{~h}$ at $37^{\circ} \mathrm{C}$. Chitinase ( $1 \mathrm{mg}$; Sigma) was used in a similar way to that described for proteinase.

\section{Blocking of mannose receptors on neutrophils}

$\mathrm{D}(+)$ mannose in PBS $(25 \mathrm{mg} / \mathrm{ml})$ was added to neutrophil monolayers for $60 \mathrm{~min}$ at $37^{\circ} \mathrm{C}$. The mannose solution was then removed and arthroconidia were added as for a standard monolayer assay.

\section{Statistical analysis}

All data were analysed by Student's $t$ test. As replicate experiments were performed on different days and at different times of day, the test results were compared against the control values obtained at the same time. The pooled variance and statistical significance for all control and test values were calculated to overcome the problem of day to day variability.

\section{Results}

\section{Phagocytosis of arthroconidia}

Non-opsonic ingestion of T. mentagrophytes arthroconidia by human neutrophils was clearly evident over a range of arthroconidial concentrations although at a lower level than when serum complement was present in the assay (table I). Ingestion in the presence or absence of opsonin depended upon incubation time in the monolayer assay (data not shown). A comparison with C. albicans blastoconidia showed that non-opsonic ingestion did not occur (5.4 SD $4.4 \%$ ).

\section{Opsonic requirements for phagocytosis}

Serum complement clearly promoted ingestion of arthroconidia to a significantly greater $(\mathrm{p}<0.005)$ 
Table I. Effect of arthroconidial concentration on neutrophil ingestion in the presence or absence of serum complement

\begin{tabular}{ccc}
\hline \multirow{2}{*}{$\begin{array}{c}\text { Number of } \\
\text { arthroconidia }\end{array}$} & \multicolumn{2}{c}{ Percentage (SD) ingestion* } \\
\cline { 2 - 3 } & without opsonin & with serum complement \\
\hline $5 \times 10^{4}$ & $18 \cdot 3(3 \cdot 5)$ & $41 \cdot 0(6 \cdot 2)$ \\
$1 \times 10^{5}$ & $23 \cdot 1(4 \cdot 1)$ & $44 \cdot 4(4 \cdot 4)$ \\
$3 \times 10^{5}$ & $31 \cdot 9(4 \cdot 9)$ & $40 \cdot 0(5 \cdot 4)$ \\
$5 \times 10^{5}$ & $24 \cdot 9(2 \cdot 1)$ & $59 \cdot 2(6 \cdot 5)$ \\
$7 \times 10^{5}$ & $26 \cdot 7(3 \cdot 7)$ & $56 \cdot 4(5 \cdot 9)$ \\
& & \\
\hline
\end{tabular}

*Percentage of neutrophils with ingested arthroconidia. All phagocytosis values represent the data for five individual neutrophil monolayers for each set of experimental conditions.

Table II. Role of anti-T. mentagrophytes serum as an opsonin

\begin{tabular}{lc}
\hline Opsonin & Percentage (SD) ingestion \\
\hline None & $19 \cdot 3(2 \cdot 8)$ \\
Serum $10 \%$ & $61 \cdot 1(5 \cdot 2)$ \\
Antiserum $10 \%$ & $40 \cdot 5(0 \cdot 7)$ \\
Antiserum $10 \%$ +antigen & $25 \cdot 7(3 \cdot 4)$ \\
\hline
\end{tabular}

Table III. Effect of exposing $T$. mentagrophytes arthroconidia to site-specific enzymes on neutrophil phagocytosis

\begin{tabular}{|c|c|c|c|}
\hline \multirow{2}{*}{ Opsonin } & \multicolumn{3}{|c|}{ Percentage (SD) ingestion after exposure to } \\
\hline & trypsin & proteinase & chitinase \\
\hline None & $18 \cdot 6(4 \cdot 0)$ & $6 \cdot 3(1 \cdot 5)$ & $4 \cdot 5(3 \cdot 5)$ \\
\hline Serum & $34.0(1 \cdot 4)$ & $4 \cdot 0(1 \cdot 0)$ & $20 \cdot 6(5 \cdot 1)$ \\
\hline
\end{tabular}

level than that seen for arthroconidia in the absence of opsonin (table II). Specific antiserum promoted ingestion $(40 \%)$, but when an antigenic extract of $T$. mentagrophytes was added to the antiserum before addition to the ingestion assay, the level of ingestion was reduced to a level not significantly different from that seen in the absence of an opsonin ( $p>0 \cdot 1)$.

\section{Phagocytosis of arthroconidia exposed to enzymes}

Exposure of arthroconidia to trypsin inhibited complement binding as expressed by a reduction in ingestion to $34 \%$ (table III). Trypsin did not increase or decrease the level of non-opsonic ingestion. Proteinase treatment reduced ingestion to negligible levels. Chitinase had a similar effect but some complement binding occurred (20.6\% ingestion).

\section{Blocking of mannose receptors on neutrophil membranes}

In an attempt to determine the contribution of mannose-specific attachment in neutrophil ingestion of arthroconidia, $\mathrm{D}(+)$ mannose was added to glassadherent neutrophils. The monolayers were washed
Table IV. Effect of adding mannose to human neutrophils prior to arthroconidia phagocytosis

\begin{tabular}{lc}
\hline Opsonin & Percentage (SD) ingestion \\
\hline None & $18 \cdot 7(3 \cdot 4)$ \\
Serum & $36 \cdot 6(4 \cdot 9)$ \\
\hline
\end{tabular}

and arthroconidia were then added. Non-opsonic ingestion was not affected but the level of complementdependent phagocytosis was significantly reduced from $60 \%$ to $36.6 \%(\mathrm{p}<0.01)$ (table IV).

\section{Discussion}

In dermatophytosis, effector mechanisms that contribute to the control of fungal growth in the epidermis are poorly understood. It is evident that infiltration of macrophages and neutrophils occurs before the peak of infection in experimental models. ${ }^{13}$ Although dermatophyte antigens are chemotactic in vitro for human neutrophils, ${ }^{14,15}$ the role of such cells in defence against dermatophytes has not been firmly established. Furthermore, Dahl and Carpenter ${ }^{6}$ showed that neutrophils adhered well to fungi provided the fungal hyphae had been pre-incubated with fresh human serum as a source of complement. These and other studies used saprophytic microconidia as target cells in various biological assays to assess phagocytosis and intracellular killing. The present study specifically examined the interaction between tissue phase arthroconidia of T. mentagrophytes and human neutrophils.

Generally, fungi are only phagocytosed after they have been opsonised. The role of opsonins in the binding of fungal cells such as blastoconidia of $C$. albicans and conidia of Aspergillus fumigatus is indisputable. Complement activation results in an accumulation of neutrophils but many areas of the body are poor in complement (e.g., lungs, cerebrospinal fluid and skin), and, because many micro-organisms interact with phagocytic cells in serum-free systems in vitro, there must be a number of mechanisms of nonopsonic phagocytosis. Some micro-organisms are able to adhere to neutrophils in the absence of antibody or complement. Adhesins are important components that mediate adherence of micro-organisms to neutrophils in the absence of opsonin. Based on bacterial systems, two major non-opsonic recognition mechanisms are known, and a considerable amount of information on the chemical nature of the complementary molecules on the bacteria and phagocytes is available. The more thoroughly studied mechanism, termed lectinophagocytosis, is based on recognition between surface lectins on one cell and surface carbohydrates on the adjacent cell. The other involves protein-protein interaction via the Arg-Gly-Asp peptide sequence.

The few studies on dermatophyte cell and human phagocyte interactions have focused on complement- 
dependent systems. Indeed, the present study confirmed that maximal phagocytosis of arthroconidia is promoted by complement and specific antibody. These findings suggest that direct and specific recognition between molecules on the arthroconidial surface and complementary structures on the phagocyte surface exist as an alternative mechanism of phagocytosis.

Of direct relevance to the binding of neutrophils to dermatophyte conidia is the presence of unique resistant layers in the arthroconidial wall. In contrast to the saprophytic microconidia, $T$. mentagrophytes arthroconidia do not possess a rodlet layer on their surface. ${ }^{16}$ Instead, they have another type of resistant layer in the cell wall. ${ }^{17}$ The mature arthroconidia of $T$. mentagrophytes are surrounded by a thick inner wall, which is synthesised de novo during arthroconidiogenesis, and by the outer wall, the remnant of the hyphal wall. ${ }^{18}$ Chemically, two-thirds of the isolated arthroconidial wall is chitinous in nature and comprised of two distinct forms of chitin: the chitinasesensitive microfibrillar form and the chitinase-resistant non-fibrillar form. ${ }^{17}$ This unique chitin-rich layer may be responsible for the resistance of arthroconidia to antifungal agents. In the present study, both proteinase and chitinase reduced the level of non-opsonic phagocytosis of arthroconidia, suggesting that outer surface components of the arthroconidial cell wall are implicated in binding and phagocytosis in the absence of opsonin.

Lectins on the arthroconidial wall may facilitate non-opsonic phagocytosis. The data from the present study suggest that lectinophagocytosis is mediated by interaction of cell-wall lectins with mannose-containing glycoproteins on the phagocyte surface. Mannose was an effective inhibitor of phagocytosis when added to neutrophil monolayers in the presence of serum. This suggests that mannose receptors on the phagocyte membrane were partially blocked when arthroconidia were opsonised, but the level of non-opsonic binding

\section{References}

1. Ahmed AR. Immunology of human dermatophyte infections. Arch Dermatol 1982; 118: 521-525.

2. Aljabre SHM, Richardson MD, Scott EM, Shankland GS. Germination of Trichophyton mentagrophytes on human stratum corneum in vitro. J Med Vet Mycol 1992; 30: $145-152$.

3. Aljabre SHM, Richardson MD, Scott EM, Rashid A, Shankland GS. Adherence of arthroconidia and germlings of anthropophilic and zoophilic varieties of Trichophyton mentagrophytes to human corneocytes as an early event in the pathogenesis of dermatophytosis. Clin Exp Dermatol 1993; 18: 231-235.

4. Ackerman AB. Subtle clues to diagnosis by conventional microscopy. Neutrophils within the cornified layer as clues to infection by superficial fungi. Am J Dermatopathol 1979; 1: $69-75$.

5. Jones HE, Reinhardt JH, Rinaldi MG. Acquired immunity to dermatophytes. Arch Dermatol 1974; 109: 840-848.

6. Dahl MV, Carpenter R. Polymorphonuclear leukocytes, complement, and Trichophyton rubrum. J Invest Dermatol 1986; 86: $138-141$

7. Schroder JM. Chemotactic cytokines in the epidermis. Exp Dermatol 1992; 1: 12-19. and ingestion was not reduced. Whether the mannosespecific attachment to phagocytes will lead to ingestion and killing appears to depend on the underlying surface properties of the fungal cell.

Other mechanisms of non-opsonic ingestion of dermatophyte arthroconidia are suggested by the present data but have yet to be explored. In a number of bacterial-effector cell interactions, surface hydrophobicity correlates with the ability of microbial cells to bind to phagocytic cells. It is possible, that surface hydrophobins serve to overcome repulsive forces between the fungal and phagocytic surfaces to allow more specific interactions to take place with higher avidity. An alternative suggestion is that a rough hydrophobic surface may facilitate phagocytosis, whereas a smooth hydrophilic one will counteract ingestion in the absence of an opsonin.

Another serum factor other than complement or antibody that functions as an opsonin is lipopolysaccharide binding protein. This protein is an acute-phase reactant that binds bacterial liposaccharide. Lipopolysaccharide binding protein can bind to the surface of gram-negative bacilli and strongly enhances attachment of these particles to the CD-14 molecule in the cell membrane of phagocytic cells. Whether such a mechanism promotes binding of dermatophyte arthroconidia to neutrophils remains speculative.

In the present study, opsonisation of the arthroconidia was not required to initiate phagocytosis, unlike the requirement for serum complement or specific antibody as opsonins for $C$. albicans. The results indicate that phagocytosis of dermatophyte arthroconidia relies on an alternative mechanism for the recognition of an invading micro-organism. Selective removal of cell-wall components before phagocytosis indicated direct and specific recognition between molecules on the microbial surface and complementary structures on the phagocyte surface.

8. Hay RJ, Calderon RA, Mackenzie CD. Experimental dermatophytosis in mice: correlation between light and electron microscopic changes in primary, secondary and chronic infections. Br J Exp Pathol 1988; 69: 703-715.

9. Calderon RA, Shennan GI. Susceptibility of Trichophyton quinckeanum and Trichophyton rubrum to products of oxidative metabolism. Immunology 1987; 61: 283-288.

10. Calderon RA, Hay RJ. Fungicidal activity of human neutrophils and monocytes on dermatophyte fungi, Trichophyton quinckeanum and Trichophyton rubrum. Immunology 1987; 61 : 289-295.

11. Hashimoto $\mathrm{T}$. Infectious propagules of dermatophytes. In: Cole GT, Hoch HC (eds) The fungal spore and disease initiation in plants and animals. New York, Plenum Press. 1991: 181-202.

12. Richardson MD, Smith $H$, Resistance of virulent and attenuated strains of Candida albicans to intracellular killing by human and mouse phagocytes. $J$ Infect Dis 1981 ; 144: $557-564$.

13. Hay RJ, Calderon RA, Collins MJ. Experimental dermatophytosis: the clinical and histopathological features of a mouse model using Trichophyton quinckeanum (mouse favus). J Invest Dermatol $1983 ; 81: 270-274$.

14. Davies RR, Zaini F. Trichophyton rubrum and the chemotaxis of polymorphonuclear leukocytes. Sabouraudia: J Med Vet Mycol 1984; 22: 65-71. 
15. Davies RR, Zaini F. Enzymic activities of Trichophyton rubrum and the chemotaxis of polymorphonuclear leucocytes. Sabouraudia: J Med Vet Mycol 1984; 22 : 235-241.

16. Hashimoto $\mathrm{T}$, Wu-Yuan $\mathrm{CD}$, Blumenthal $\mathrm{HJ}$. Isolation and characterization of the rodlet layer of Trichophyton mentagrophytes microconidial wall. $J$ Bacteriol 1976; 127: 1543-1549.
17. Pollack JH, Lange CF, Hashimoto T. "Nonfibrillar" chitin associated with walls and septa of Trichophyton mentagrophytes arthrospores. J Bacteriol 1983; 154: 965-975.

18. Hashimoto T, Emyanitoff RG, Mock RC, Pollack JH. Morphogenesis of arthroconidiation in the dermatophyte Trichophyton mentagrophytes with special reference to wall ontogeny. Can J Microbiol 1984; 30: 1415-1421. 